\title{
Reflections of the Cultural Differences between China and Pakistan and Corresponding Suggestions
}

\author{
Yin Zhu \\ School of Foreign Languages \\ North China Electric Power University, NCEPU \\ Beijing, China
}

\begin{abstract}
The paper reports and compares the cultural differences between China and Pakistan and gives corresponding suggestions in order to reduce the barriers of cross-cultural communication. Based on the research and theories of predecessors, this paper analyzes the reflections of these differences and classifies them from the aspects of religion, customs and ideologies. The result presents that the cultural differences between China and Pakistan are multiple and reflected in every area of life. However, with correct attitudes and proper actions, barriers can be reduced and better crosscultural communication can be achieved.
\end{abstract}

Keywords-Cultural

differences;

Cross-cultural communication; Religion; Customs; Ideologies; Suggestions

\section{INTRODUCTION}

Pakistan has been an important strategic partner of China for a long time and Sino-Pakistan relationship has been increasingly strengthened especially in recent decade years. However, the focuses between the two countries are always limited in the aspects of politics, military and economy and researches about culture and cultural differences so insufficient that we are in badly need of such academic researches. Crosscultural communication area has made abundant achievements as Professor Sun Youzhong and professor Guan Shijie have established comprehensive and systematic theories. However, there is still a lack of researches especially for China and Pakistan. So far, the limited resources of published papers mainly include Analysis on the Intercultural Communication between Chinese and Pakistanis (Zhao Fei), Cultural Differences between China and Pakistan in the Case of Cross Cultural Communication (Wang Lihua), A Comparative Study on Mate Selection and the View of Marriage of University Students of China and Pakistan (Qiao Qingshui), etc. These papers analyze Pakistani culture from different aspects but they are all in Chinese version and most of them just present one single view. Besides, there aren't enough and concrete suggestions either. Some important literatures in English are: Pakistan: Its People, Its Society, Its Culture (Donald N.Wilber and Donold Atwell), Renaissance of Islamic Culture and Civilization in Pakistan (Abdur Rauf), etc. They introduce the Pakistani society and its development of civilization. It is a pity that it had been many years since their publications and some of the information is outdated or no longer suitable to the modern society.

In a word, literature in English for comprehensive overviews of comparisons between religions, customs and ideologies in China and Pakistan are much less than those in other areas.

\section{BACKGROUND}

\section{A. Relationship}

China and Pakistan are neighbor countries both with great history and splendid civilization. There has been a traditional friendship between the two countries, which can date back to 1000 years ago. Especially in modern times, Pakistan is one of the most important strategic partners in the world. "Since the establishment of diplomatic relationship 55 years ago, the allweather friendship between Pakistan and China has withstood the test of time and is maturing by the day." [1] In the last few years, Chinese government proposed "One Belt, One Road" initiative project and one of the first initiative under this project is the China-Pakistan Economic Corridor (CPEC). "China is rising as a big power of the world; therefore Chinese government has decided to connect the China with the whole world to increase her trade and other economic activities." [2] Under such background, the role played by Pakistan is increasingly important and the cooperation between China and Pakistan covers from economy and politics to technology and culture. "The development of this project has multifold benefits but especially it is more beneficial to Pakistan economic development." [3] Needless to say, the communication between China and Pakistan will increase not only at a national level, but from an individual level.

\section{B. Conflicts caused by cultural differences}

Culture, according to the definition given by Hofstede, is the collective mental programming of the people in an environment, conditioned by the same education and life experience. People are shaped by multi-level factors and different environments they are exposed to will breed different ideologies. "Cultural conflict situations are situations in which different groups in society have different conduct norms for the same situation." [4] That is to say, people with diverse backgrounds are bound to have conflicts caused by culture in communication. This universal phenomenon which is inevitable and cannot be eliminated radically occurs more and more due to the pace of globalization. What can be done is to study and weaken the cultural conflicts. 


\section{Communication barriers between China and Pakistan}

China has been influenced by Confucianism for a long time while Pakistan is a country with firm belief in Islam, which gains the two countries distinctive cultural features. According to Zhao Fei's research, in the communication between people in China and Pakistan, the occasion in which they are not satisfied with people in the other country takes up to about 80 per cent and the situation shows no trend of getting better with further communication. This means that there are culture and tradition differences between the two countries and there are also some cultural barriers that obstruct the communication between China and Pakistan. Thus, the exploration of this topic is of great significance.

\section{SPECIFIC MANIFESTATIONS}

\section{A. Religion}

Generally speaking, Pakistan is a Muslim country with about 97per cent of people believing in Islam. As a result, Islam is the national religion and exerts great influence on all aspects of life. People can feel a strong religious atmosphere in Pakistan. Whether modern cities or remote rural regions are all dotted with mosques. Children even begin to recite the Quran, the holy scripture of Islam at the age of three. "If they find such a scrap, it will immediately be picked up and put in a higher place out of respect. Copies of the Quran are found in every house, wrapped in several layers of elaborate cloth covering and kept on the highest shelf of the cupboard." It can be seen clearly what great impact the religion has on Pakistani people. And such influence is so powerful that a large part of social activities, traditions, customs are centered on it and the religion further affects the values, culture and ways of thinking and behaving of people in Pakistan. Categorized by the control and restraint force, Islam is one of the most powerful religions in the world. Such power is not abstract at all and is obvious to all. Therefore, Pakistan, a religious country, presents a totally different society compared with China. And it is the religious differences that form the sources and origins of the cultural differences between China and Pakistan. "Allah - there is no deity except Him, the Ever-Living, the Sustainer of [all] existence. Neither drowsiness overtakes Him nor sleep. To Him belongs whatever is in the heavens and whatever is on the earth." (Quran Chapter 2 Section 255) [5] Pakistanis has a concrete object to worship which is supreme. The strong belief of Allah forms the basis of their outlooks of world, life and value. "He gives life and causes death, and to Him you will be returned" (Quran Chapter 10 Section 56) [5] "Wherever you may be, death will overtake you, even if you should be within towers of lofty construction." (Quran Chapter 4 Section 78) [5] The faith in Allah instructs people to obey their fate. Since everything has been arranged already, there is no need to fight against destiny and any defiance is meaningless. Actually, Islam in Arabic language means obedience. Hence, Muslims have little resistance against the current situation and they pin their hopes largely on the afterlife. The happiness in the world to come is more significant than that in this life.

Even though China doesn't has a religion that is so widely accepted nationwide, Chinese people are influenced by Confucianism to a certain degree. In a strict sense,
Confucianism doesn't belong to religion. However, it has developed and ruled people's mind as an official thought for more than two thousand years in China, which gains Confucianism a religious-equal status. In this respect, Confucianism goes beyond a religion. It imposes subtle impacts on Chinese people's mind even without their awareness. "The religious idea of Confucianism is revealed by the endless potential and strength during the process in which a person transcends himself."'(In Chinese) [6] Confucianism focuses on the improvement of individuals to make contribution to the real world and on the transformation of this life. There isn't any god or lord to worship, so Confucianism puts emphasis on individuals. That's the fundamental differences between the two countries.

\section{B. Customs}

\section{1) Communication}

"Good morning" or "hello" is not a typical way for Pakistani people to greet each other. Instead, almost all of them greet one another with "Assalamualaikum" (peace be on you) and reply with "Waalaikum assalam" (and on you peace). No matter what age they are, what kind of job they have, how much they are familiar with each other, such greeting suits all situations. And in some regions, it is a polite gesture to put your right hand on the heart. And it is customary for a Pakistani to reply "Alhamdulillah" (praise God) or "Khuda ka shuker hai" (thank God) when his health or families are asked regardless of the fact. The greetings in China usually begins with the concern about meals like "Have you eaten?" between friends or just a simply "hello" between acquaintances. At the same time, Chinese people will pat each other on shoulders or back to express intimacy which is replaced by shaking hands or embracing in Pakistan. Rather than showing sincerity and concentration in China, eye contact should be avoided when communicating with Pakistani people because it is considered impolite and rude. According to the research made by Zhao Fei, China is a state of ceremonies and most Chinese people use polite expressions in communication. Yet, Pakistanis even use honorific more frequently. The fact is that there is a particular tense and voice in Urdu for polite expressions. Hand gestures are understood differently in Pakistan. For example, thumb-up gesture has quite an opposite meaning of praise. It is a kind of insulation and offence equivalent to the middle finger.

\section{2) Food}

Generally speaking, the cuisines in Pakistan vary from region to region, but they share some common features. Firstly, spicy flavor and curry are popular nationwide, whether with meat of vegetables. "Bland food is considered fit only for an ill person." [7] Food with strong flavor is preferred by Pakistani. Secondly, food in Pakistan is mainly braised. And Pakistani are not accustomed to combining meat and vegetables together, which has nothing to do with the taste, but a kind of cooking habits. Thirdly, since Muslims are not allowed to eat pork or drink alcohol, they must strictly observe halal dietary guidelines. Any kind of alcohol cannot be found in this country but chicken, beef and lamb are available almost everywhere. In addition, neither chopsticks nor forks can be found on the table. The routine is eating with hands, such as breaking chapati into 
small pieces or sending rice to the mouth with fingers. And in this respect, it must be the right hand.

Divided into eight big cuisines, or say, eight styles, food in China is more varied and sauting is the most common cooking style. There isn't any particular prohibition about food in China. Using chopsticks and spoons are taught by parents to every child from an early age and eating food with hands is regarded as impolite and lack of upbringing.

\section{3) Festival}

As a religious country, one of the most important festivals in Pakistan is Ramadan which means "the month of forbiddingness" and Lesser Bairam that marks the end of the Ramadan. Adult Muslim must strictly fast from early dawn to the sunset (usually from 3a.m to 16p.m). "Those who are exempted from fasting, such as the elderly or nursing mothers do not eat or drink in public out of respect to the others." [7] During the whole month, people are not allowed to eat in the daytime and all the catering industries shut down. Generally, people have iftar (evening meal) and suhoor (pre-dawn meal) before the dawn. Fasting is one of the five basic lessons of Islam: affirmation, prayer, almsgiving, fasting, and pilgrimage. In the month of fast, Muslims also go to Mosque for praying with a special kind of prayer called "Taraweeh prayer" that is two to three times as long as the normal one. Lesser Bairam comes on the second day after the end of the Ramadan. It is the festival that the entire Muslim world celebrates excitedly. There are three days off for this festival. Dressed in their holiday best, people gather together for different kinds of entertainments or visit their relatives and friends.

The main reason for the Ramadan is to commemorate the birth of Contrary. Meanwhile, it also offers Muslims an opportunity to control and purify one's mind and soul. People believe that when food is no longer paid attention to, the distance between Allah and them is shortened and thus the piousness is shown.

As to China, the most important festival should be the Spring Festival. It has nothing to do with the religion and the joy with families and feasts with abundant and delicious food are given priorities.

\section{4) Others}

Left hand is regarded as dirty. As a tradition, left hand deals with something unclean. It is such a strong and deep-rooted custom that even those Pakistani people who are used to using their right hand have to learn to eat with their right hand. As a result, it is of great importance to distinguish different situations and use the proper hands otherwise it may cause offence. Although China also takes right hand for honor and dignity, the boundary of good and bad between two hands is not as clear as that in Pakistan. When it comes to color, yellow, which represents honor, dignity and glory in China, may probably arouse political and religious disgust because Brahmanism in Pakistan wear yellow robes (In Chinese) [8]. Contrary to the negative meaning of green in China particularly to male, green is the color of holy, pure and solemnity in Pakistan and that's why it can be seen in the national flag and mosques. The work and rest time is quite different between the two countries, especially reflected in meal time with almost a three hours gap as Chinese people usually have lunch at around 11a.m. to 12 o'clock and dinner at around 5 to 6 p.m. while Pakistani people have lunch at 1to 2p.m and dinner at 8 to 9 p.m as a rule. And twice a day, at about 11.30 a.m. and 3.30 p.m., there is a break for tea time lasting for 20 minutes.

\section{Ideology}

\section{1) Social view}

Taking the history and current situation into consideration, people in Pakistan have been experiencing great changes of regime, culture and religion that they are adaptable and tolerant.

According to the creeds in the Quran, everything in life is arranged by God and Pakistanis believe in fate. So it is nobody that should be to blame for or take responsibilities for failures which are considered as acts of God. If a calamity or tragedy unfortunately occurs to someone, others will comfort each other with the word kismet. Although in China humility and mildness are national ethos, introspection and self-criticism are absolutely necessary after a failure and the person who is supposed to be in charge will be investigated and hold responsibility.

The gap of social ranks is much bigger in Pakistan than that in China. Ranks used to be highly emphasized in China in the ancient time. But nowadays, with the thoughts of freedom, equality and ruling-by-law, sense of hierarchy is weakening. For the record, under no circumstance can such hierarchy go against the law or moralities. In contrary, eating with people who have lower ranks even now is not widely accepted in Pakistan. Pakistani people usually try to please those who are their superiors either in workplace or at home. That can be the reason why in China more employees choose to change a job when they are not satisfied with the boss while Pakistani people are more likely to bear.

\section{2) Gender view}

According to Hofstede's theory of measurement of cultural value, gender view is also an importance dimension which reveals cultural differences. In China, gender equality is what the whole society pursues. But in Pakistan, gender discrimination is so common and normal that almost everyone takes it for granted. "Culturally, women are seen as inferior to men and are expected to be obedient to their husbands and other male members of the family." [7] From this, the gender discrimination goes without saying. In Pakistan, there are strict restrictions in interacting between a male and a female. Generally speaking, female should avoid being exposed to the public as much as possible. When communicating with the opposite sex, a certain distance is necessary and any form of physical touching is improper. Even a request for taking photos with females may make them embarrassed. A man will not take his wife to social activities and meanwhile the female is seldom invited to such occasion. If so, very few of them would be present. It is quite common that the hostess of a family doesn't show up when some guests come to visit. All above are not regarded as rude or impolite because they are just a reflection of Pakistani culture. Contrarily, in China, especially recent years, gender discrimination is almost eliminated. Women play as important role as men in all walks of life and receive the same popularity in workplace. 


\section{3) Marriage view}

Greatly influenced by the religion, Pakistan is a much more conservative country in which romance is a taboo. A relationship between a boy and a girl not aiming at marriage is not allowed. Thus, dating is not common. Before the marriage is prospected, the relationship is kept secret and young people are restrained to show love in the public. Most Pakistani girls are traditional and want to get married. A large portion of marriages are arranged by parents. From the process of a couple getting married, it can be seen that the marriage is not a produce of love but a need for some particular purposes and every step has rules to follow. The marriage view of Pakistani people is generally based on traditional culture and in accordance with religious demands. "In line with traditional Pakistani culture, marriage is a place for love, for offering children a peaceful life and for satisfaction of emotion and sex." (In Chinese) [9] Chinese people keep a relatively open mind to the marriage and their understanding of marriage is more rich and subtle and more modern elements are taken into consideration, which increases the freedom and flexibility of the marriage.

\section{4) Time view}

The loose time view of Pakistani people is in contrast with that of Chinese people. There is an old saying in China that "Time is money" which expresses obviously Chinese people's attitude towards time. In their eyes, every second is so valuable that is equivalent to the gold. So pedestrians in the street are always in a hurry. Being late is annoying and will be criticized if there is no acceptable reason. Arriving on time or several minutes earlier is a convention in Chinese society. In Pakistan, because of the worship and tea time twice a day, their time schedule is quite loose. Compared with the supreme reverence to the God, time is not so important. Even if they were late or behind the schedule, they would still follow their own pace. Such phenomenon is particularly evident in government jobs. Finding an excuse for absence is easy and normal. In their mind, being late is not a big deal and people are so used to it that no one would take it seriously. "Funerals and sickness are common excuses and the official four days off when a public holiday is merged with the weekend can easily become six or even eight days." [7]

\section{SOLUTIONS}

\section{A. Attitudes}

About the relationship between one culture and another, "there are two completely opposite ideas: one is cultural relativism and another cultural absolutism. The former believes that every culture is unique and denies the common character and the possibility as well as the necessity of mutual communication between cultures. The latter believes that some civilizations are superior to others and the backward culture must be replaced by the advanced one to realize the universal harmony of human culture." (In Chinese) [10] Both having their own political purposes, these two ideas are undesirable. First of all, the recognition of cultural diversity should be established. According to Sun Youzhong's theory, a culture has features of inheritance, acquisition and function. As a result, culture is inevitably diverse for which must admit, accept and cherish. Every culture is equal, every culture has its own value that deserves being respected and every culture has the right to develop itself. Any thought of superiority and inferiority is groundless and ridiculous. Only when we respect each other from the heart instead of being self-centered and blindly proud, can we bear an open mind. That's not enough. We should show tolerance to the exotic customs whether we are confused to them or not or whether we like them or not. Last but not least, with all these cultural differences, we should still hold the ground that the cross-cultural communication is not impossible and the barriers caused by cultural differences are not insurmountable.

\section{B. Actions}

In terms of the knowledge about cross-cultural communication, we should know more about Pakistan in various aspects, such as religion, history, customs, politics, education and so on. Besides, the improvement of the basic communicating skills is also required. What's more, we can take part in cross-cultural activities as much as possible. Get in touch with local people and try to make friends with them. In the interaction, personal experience is conducive to being integrated in the cultural atmosphere. And further contact helps to reduce the misunderstanding and prejudice against another culture. Nothing is easy at the very beginning but we need to try to overcome the obstacles we might meet and take real actions. In addition, we should also pay attention to the crosscultural cases happening around us, analyze the causes and deep reasons behind them and reflect ourselves to adjust and correct our behaviors so that the cross-cultural communication awareness can be better established. On the other hand, transmitting our own culture is equally important. Comprehending cultural differences should be bidirectional. This process happens step by step and cannot be accomplished within a day. Learn from each other, absorb the essence and discard the dross to improve the culture we have already had. Any form of entire affirmation or denying is unwise. We should always bear in mind that our national culture is the base for us to stand on. No matter adjustment will be made; our roots and traditions never sway. What needs to be noticed is that however the conflicts caused by different cultures might be, there is no reason to resort to solution through the use of force.

\section{SUMMARY}

The Sino-Pakistan relationship is becoming closer and the communication between the two countries is increasing. Because of the different backgrounds, cultural differences in China and Pakistan are prominent which result in cross-cultural communication barriers for people in the two countries. Such cultural differences mainly manifested in religious area, customs area and ideological area in which communication, diet, festival and others, social view, gender view, marriage view and time view play important roles. With all these differences, better cross-cultural communication can still be achieved. We should not only take correct attitudes towards this case, but also take proper actions. Only when we admit the diversity of cultures and respect each other, can we put idea of improving communication into practice and make some differences from the action. 


\section{REFERENCES}

[1] Jiang Shuxian. 55 years of relationship between China and Pakistan: friendship and cooperation [J]. China and World, 2006(3): 21-24

[2] Bi, M. (2013). Transcript: Pakistani Prime Minister Gives Exclusive Interview to Xinhuanet.XinhuaNet, 6July,2013.http://news.xinhuanet.com/english/china/201307/06/c_132516529.htm (retrieve on December 9, 2015).

[3] Kanwal Asma \& Zheng Lu \&Xiang Deng. Strategic influence of "One Belt, One Road" on Pakistan economic development: a case study on CPEC $[C]$. Chengdu: Sichuan University

[4] Tamar Tomer-Fishman. "Cultual defense," "cultual offense," or no culture at all?: an empirical examination of Israeli judicial decisions in cultural conflict criminal cases and of the factors affecting them [J]. The
Journal of Criminal Law and Criminology (1973-), Vol. 100, No. 2 (Spring 2010), pp. 475-522.

[5] The Quran from http://tanzil.net.

[6] Du Weiming. The religion of confucianism, Wuhan : Wuhan University Press, 1999.

[7] Safia Haleem. Pakistan-culture Smart! Beijing: Higher Education Press, 2017.

[8] Wang Lihua, Cultural differences between China and Pakistan in the case of cross cultural communication [J]. Shenyang: Liaoning University.

[9] Qiao Qingshui. A comparative study on Mate selection and the View of Marriage of University Students of China and Pakistan [M]. Hebei: Hebei University, 2014.

[10] Sun Youzhong. About cultural communicationism, Beijing: Beijing Foreign Studies University. 